\title{
Focusing and defocusing of tropical cyclone generated waves by ocean current refraction
}

Rui Sun ${ }^{1}$, Ana B. Villas Bôas ${ }^{1}$, Aneesh C. Subramanian ${ }^{2}$, Bruce D. Cornuelle $^{1}$, Matthew R. Mazloff ${ }^{1}$, Arthur J. Miller ${ }^{1}$, Sabique Langodan ${ }^{3}$, Ibrahim Hoteit ${ }^{3}$

\footnotetext{
${ }^{1}$ Scripps Institution of Oceanography, California, USA

${ }^{2}$ Department of Atmospheric and Oceanic Sciences, University of Colorado Boulder, Colorado, USA

${ }^{3}$ Physical Sciences and Engineering Division, King Abdullah University of Science and Technology
}

(KAUST), Thuwal, Saudi Arabia

\section{Key Points:}

- Altimeter data and WAVEWATCH III are used to quantify ocean current impacts on surface waves.

- Coherent wave beams propagate from tropical cyclone eyewalls due to current-induced refraction.

- Wave height structure is dominated by background currents, and not the cyclone induced currents.

Corresponding author: Rui Sun, rus043@ucsd.edu

This article has been accepted for publication and undergone full peer review but has not been through the copyediting, typesetting, pagination and proofreading process, which may lead to differences between this version and the Version of Record. Please cite this article as doi: 10.1029/2021JC018112.

This article is protected by copyright. All rights reserved. 


\begin{abstract}
Waves generated by tropical cyclones can have devastating effects on coastal regions. However, the role of ocean currents in modifying wave amplitudes, wavelengths, and directions is commonly overlooked in wave forecasts, despite the fact that these interactions can lead to extreme wave conditions. Here, we use satellite observations and wave modeling to quantify the effects of ocean currents on the surface waves generated during a tropical cyclone event in the Arabian Sea. As a case study, this paper documents coherent beams of wave heights originating from the eyewall of a tropical cyclone caused by current-induced refraction. Alternating regions of high and low wave heights in the model simulations are consistent with observations and extend for thousands of kilometers all the way to $100 \mathrm{~m}$ isobath. Our results highlight the importance of accounting for wave refraction by currents in order to accurately predict the impact of tropical cyclone generated waves on coastal regions.
\end{abstract}

\title{
1 Plain Language Summary
}

Waves generated by tropical cyclones can have devastating effects on coastal regions. Ocean currents can modify wave heights and lead to extreme wave conditions. Here, we use satellite observations and wave modeling to quantify the effects of ocean currents on the waves during a tropical cyclone event in the Arabian Sea. In this paper, we documented the coherent beams of wave heights originating from the "center" of a tropical cyclone caused by current-induced effects. Alternating regions of high and low wave heights in the model simulations are consistent with observations and extend for thousands of kilometers all the way to $100 \mathrm{~m}$ isobath. Our results highlight the importance of accounting for the currents in order to accurately predict the impact of tropical cyclone generated waves on coastal regions.

\section{Introduction}

Ocean surface waves mediate exchanges of momentum and energy across the airsea interface. Thus, representing waves in weather and climate models is crucial for improving predictive skill (Cavaleri et al., 2012; Villas Bôas et al., 2019). Moreover, surface waves are an important driver of beach erosion, pollutant transport, and coastal flooding; hence understanding the evolution and propagation of surface waves and accurately modeling them has profound implications for both the coastal and global communities (Munk \& Traylor, 1947).

Surface waves are generated by the wind, and extreme wind events, such as tropical cyclones, can produce extreme waves. Waves are affected by ocean currents via wavecurrent interactions, which modify their amplitude, wavelength, and direction. Recent numerical modeling studies have shown that the spatial variability of significant wave height $H_{s}$ (the average of the highest one-third of the wave heights) at scales between 10 and $100 \mathrm{~km}$ is governed by the gradients in ocean currents (Ardhuin et al., 2017; Romero et al., 2020; Villas Bôas et al., 2020; Marechal \& Ardhuin, 2021). Despite the limited spatial sampling of present satellite altimeters, novel signal processing techniques have provided observational evidence that supports these numerical results (Quilfen et al., 2018; Quilfen \& Chapron, 2019).

In the context of tropical cyclones, several studies have explored the effects of currents on surface waves (Holthuijsen \& Tolman, 1991; Fan, Ginis, Hara, Wright, \& Walsh, 2009; Fan, Ginis, \& Hara, 2009; Warner et al., 2010; Olabarrieta et al., 2012; Chen et al., 2013; Drost et al., 2017; Mogensen et al., 2017; Liu et al., 2017; Hegermiller et al., 2019; Abolfazli et al., 2020; Prakash \& Pant, 2020). For example, Holthuijsen and Tolman (1991) performed a theoretical study on the interaction between a Gulf Stream eddy and ocean waves in swell and storm conditions. In their study, the wave model captured 
current-induced wave refractions that led to considerable variation in significant wave height. In addition, Fan, Ginis, and Hara (2009) used a coupled wind-current-wave model to study processes at the air-sea interface under an idealized tropical cyclone scenario, and examined their effects on the wave field, wind stress, and ocean currents. Although the authors explored some aspects of wave-current interaction, their experiments only considered the effects of tropical cyclone generated currents. Recently, Hegermiller et al. (2019) studied wave-current interactions during Hurricane Matthew and found that the Gulf Stream modified the maximum coastal total water levels and resulted in the incident wave directions at the coast changing by up to $20^{\circ}$. However the Gulf Stream vorticity structure varies mostly cross-shore, and for the Hurricane Matthew case wave refraction was less significant in determining the spatial variability of the wave field. Here, in this case study, we report that far-field $H_{s}$ from tropical cyclone generated waves can vary by meters due to refraction by background ocean currents. Building on the theoretical analysis by Holthuijsen and Tolman (1991), we validate model results with altimetry, providing observational evidence that tropical cyclone driven waves can have $H_{s}$ variability of meters due to wave-current interactions.

The present study examines the surface wave field during Cyclone Mekunu in the Arabian Sea from a numerical modeling perspective and validates the results with satellite altimetry observations. We show how surface waves propagating away from the eyewall of a tropical cyclone have current-induced variations in $H_{s}$ of up to $2 \mathrm{~m}$ within scales of hundreds of kilometers. The Arabian Sea is chosen because the tropical cyclones forming there often lead to considerable destruction and loss of life due to inundations (Dube et al., 1997; Evan et al., 2011; Evan \& Camargo, 2011). In addition, continued anthropogenic forcing is likely to further amplify the risk of cyclones in the Arabian Sea and increase socio-economic implications for coastal communities in that region (Murakami et al., 2017).

The rest of the paper is organized as follows. We first introduce the design of our numerical experiments with realistic currents, without currents, and with spatially smoothed currents. Then the results from the numerical simulations are presented and validated against altimeter data. The final section discusses the results and concludes this paper.

\section{Experimental Design}

In this case study we used version 5.16 (WAVEWATCH III Development Group, 2016) of the WAVE-height, WATer depth and Current Hindcasting (WAVEWATCH III) third generation wave model (hereinafter, WW3) to investigate waves generated by $\mathrm{Cy}-$ clone Mekunu, which was the strongest tropical cyclone in the north Indian Ocean in 2018. We selected this event because it overlaps with several passes from the Jason-3 and SARAL/AltiKa satellites in the Arabian Sea, providing cross-validation of our modeled $H_{s}$. We have run simulations during other cyclones in the Arabian Sea (see the Supplementary Information) and the discussion presented here for Cyclone Mekunu applies for the other events as well.

The propagation of surface gravity waves in spectral wave models, such as WAVEWATCH III, is governed by the action balance equation:

$$
\frac{\partial N}{\partial t}+\frac{1}{\cos \phi} \frac{\partial}{\partial \phi} \dot{\phi} N \cos \theta+\frac{\partial}{\partial \lambda} \dot{\lambda} N+\frac{\partial}{\partial k} \dot{k} N+\frac{\partial}{\partial \theta} \dot{\theta} N=S_{i n}+S_{d s}+S_{n l},
$$

where $N=N(k, \theta ; \phi, \lambda, t)$ is the action spectrum, $k$ is the wavenumber, $\theta$ is the wave direction, $\phi$ is the latitude, $\lambda$ is the longitude, $t$ is the time, $S_{i n}$ is the input of action from the wind, $S_{d s}$ is the dissipation, and $S_{n l}$ represents nonlinear interactions. Additionally, the propagation velocities in physical and spectral space are given by: 


$$
\begin{aligned}
\dot{\phi} & =\frac{c_{g} \cos \theta+U_{\phi}}{R}, \\
\dot{\lambda} & =\frac{c_{g} \sin \theta+U_{\lambda}}{R \cos \phi}, \\
\dot{k} & =-\frac{\partial \sigma}{\partial d} \frac{\partial d}{\partial s}-\boldsymbol{k} \cdot \frac{\partial \boldsymbol{U}}{\partial s}, \\
\dot{\theta} & =\dot{\theta}_{D G}-\frac{1}{k}\left[\frac{\partial \sigma}{\partial d} \frac{\partial d}{\partial m}+\boldsymbol{k} \cdot \frac{\partial \boldsymbol{U}}{\partial m}\right],
\end{aligned}
$$

where $\boldsymbol{U}$ is the surface current, $R$ is the Earth's radius, $d$ is the water depth, $s$ is a coordinate parallel to the wave direction, $m$ is a coordinate perpendicular to the wave direction, $\dot{\theta}_{D G}$ is the apparent wave rotation due to the Earth's sphericity and water depth gradients, and $c_{g}=\partial \sigma / \partial k$ is the group speed, where $\sigma$ is the intrinsic frequency given by the linear dispersion relation:

$$
\sigma^{2}=g k \tanh (k d)
$$

From Eqs. (1)-(5) we see that currents and current gradients can impact the wave field by (i) changing the wind input $S_{i n}$ to account for the wind stress relative to the surface current;(ii) changing the speed at which action is advected $\left(\boldsymbol{c}_{\boldsymbol{g}}+\boldsymbol{U}\right)$; (iii) changing the wavenumber $\dot{k}$; (iv) and finally changing the wave direction $(\dot{\theta})$, i.e. causing wave refraction. The wave model setup used in the present manuscript includes all four effects, although our discussion will focus on the effects of refraction.

The model domain extends from $0^{\circ}$ to $30.6^{\circ} \mathrm{N}$ and from 30 to $78^{\circ} \mathrm{E}$ with $0.075^{\circ}$ spatial resolution in both latitude and longitude. The spectral grid of WW3 has 48 directions $\left(7.5^{\circ}\right.$ resolution) and 32 frequencies exponentially spaced from 0.0343 to $1.1 \mathrm{~Hz}$. The spatial and spectral resolution of the wave model used here are adequate to resolve the processed that focus on and increasing either spatial or spectral resolution does not impact our results (see Supplementary Information for more details). The wave spectra at the offshore boundary come from the global wave modeling system described by Rascle et al. (Rascle \& Ardhuin, 2013). The results that we analyze here span the period from May 20-28, 2018 and we allowed the wave model to spin-up for 19 days from May 01, 2018. Our implementation of WW3 uses a global integration time step of $600 \mathrm{~s}$, spatial advection time step of $60 \mathrm{~s}$, spectral advection time step of $60 \mathrm{~s}$, and minimum source term time step of $10 \mathrm{~s}$. The recently proposed T475 parameterization is used with the wind input source term $S_{i n}$ in the present simulations (Alday et al., 2021). This aims to mitigate the error in the wave model when the wind speed is larger than $20 \mathrm{~m} \mathrm{~s}^{-1}$ in ERA5. In addition, we activated the PR3 option in WW3 to alleviate the Garden Sprinkler Effect (Booij \& Holthuijsen, 1987) that can arise from coarse directional resolution by performing a spatial averaging (Tolman, 2002).

The wave model was forced with 10-m winds from ERA5 (ECMWF, 2017) and surface currents from the Global Ocean Forecasting System (GOFS) V3.1 HYCOM/NCODA $1 / 12^{\circ}$ analysis (Chassignet et al., 2007) (hereinafter, HYCOM). To evaluate the simulation performance, we compared the modeled $H_{s}$ with along-track $H_{s}$ measurements from the Jason-3 and SARAL/AltiKa altimeters. We use quality-controlled, unfiltered and not resampled, along-track $H_{s}$ measurements provided by the Institut Français de Recherche pour l'Exploitation de la MER (Queffeulou \& Croizé-Fillon, 2013) (IFREMER; ftp://ftp.ifremer.fr/ifremer/cersat/products/swath/altimeters/waves/).

The following experiments were performed:

1. WAV.CUR: The hourly ERA5 winds and daily HYCOM currents were used to force the wave model. 
2. WAV.WND: The hourly ERA5 winds were used to force the wave model. This experiment had no current forcing and it was aimed at investigating the effects of currents on the wave field.

3. WAV.CUR_STA: The hourly ERA5 winds and persistent HYCOM currents were used to drive the simulation. In this experiment, the HYCOM currents on the initial day (May 20) remain persistent through the simulation. Hence, the tropical cyclone-induced currents are not considered in this run.

4. WAV.CUR_LOW: The hourly ERA5 winds and spatially smoothed daily HYCOM currents were used to drive the simulation. The currents were averaged to $2.55^{\circ}$ resolution in each direction (approximately $288 \mathrm{~km}$ ). This run was performed to investigate the influence of current resolution.

\section{Results}

\subsection{Modeled Significant Wave Height}

The snapshots of sea level pressure and 10-m wind speed from ERA5 are presented in Fig. 1 to illustrate the evolution of Cyclone Mekunu. The cyclone started forming on May 20, 2018 and then propagated to the northwest before making landfall on May 26, 2018 (Government of India, 2018). The corresponding snapshots of significant wave height $H_{s}$ from WAV.CUR and WAV.WND are shown in Fig. 2 (a-b and $\mathrm{c}-\mathrm{d}$, respectively). In both simulations, the highest wave heights are observed near the eyewall of the tropical cyclone, reaching a maximum of over $8 \mathrm{~m}$ on May 24. In comparison with the results obtained from WAV.WND, alternating regions of high and low $H_{s}$ can be observed in WAV.CUR, particularly towards the end of the simulation (Fig. 2b). These coherent "beams" of $H_{s}$ extend from the eyewall of the tropical cyclone to the east, all the way to the $100 \mathrm{~m}$ isobath. As a consequence of wave current interactions, the significant wave heights reaching some locations near Mumbai and Karachi on May 26th are approximately $1 \mathrm{~m}$ higher in WAV.CUR than WAV.WND, with severe associated flood risk implications.

The differences of significant wave height $H_{s}$ obtained from the simulations are shown in Fig. 3. Compared with the wave field obtained from WAV.WND, alternating patterns of higher and lower waves are obtained from WAV.CUR, especially on May 26th (shown in Fig. 3b). When the impact of the tropical cyclone induced currents is not considered (WAV.CUR_STA), the pattern in $H_{s}$ observed in the far field is similar to WAV.CUR (shown in Figs. 3c and d). In WAV.CUR_LOW the currents are spatially smoothed and the alternating patterns of $H_{s}$ are much weaker compared with WAV.CUR and WAV.CUR_STA (shown in Figs. 3e and f). On May 24th, $H_{s}$ near the eyewall of the tropical cyclone $\left(12^{\circ} \mathrm{N}\right.$, $56^{\circ} \mathrm{E}$ ) in WAV.CUR and WAV.CUR_LOW is slightly smaller than WAV.WND, shown in Figs 3a and e, consistent with the results from Fan, Ginis, and Hara (2009) and Hegermiller et al. (2019). On the other hand, when the tropical cyclone induced currents are not considered (WAV.CUR_STA), there is no reduction in $H_{s}$ near the eyewall. Since the goal of this paper is to document the effect of the background currents, and thus we do not further detail the effects of tropical cyclone induced currents in this event.

\subsection{Comparison With Satellite Altimetry}

The significant wave height, $H_{s}$, obtained from all four experiments is compared with along-track altimeter data to validate our numerical results, as shown in Fig. 4. In general, all model runs capture the large-scale spatial variability of $H_{s}$ along the satellite tracks, especially in the near field of the cyclone (Figs. 4a, b, and d). The differences between the simulation results and altimeter data may be because of the uncertainties of ERA5 wind, HYCOM currents, or initial condition. However, only the experiments that include full resolution current forcing (WAV.CUR and WAV.CUR_STA) properly capture the alternating high and low beams of $H_{s}$ to the northeast of the cyclone that occur at scales of a few hundred of kilometers (Figs. 4b, and d). Although there are some 
sea level pressure

(a) UTC 0000, 05/24

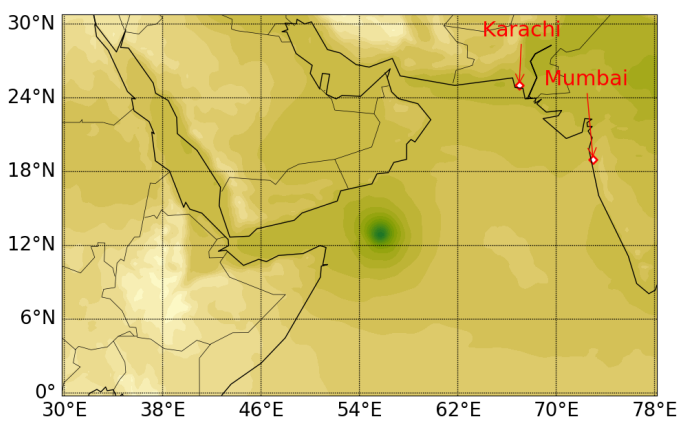

10-m wind speed

(a) UTC 0000, 05/24

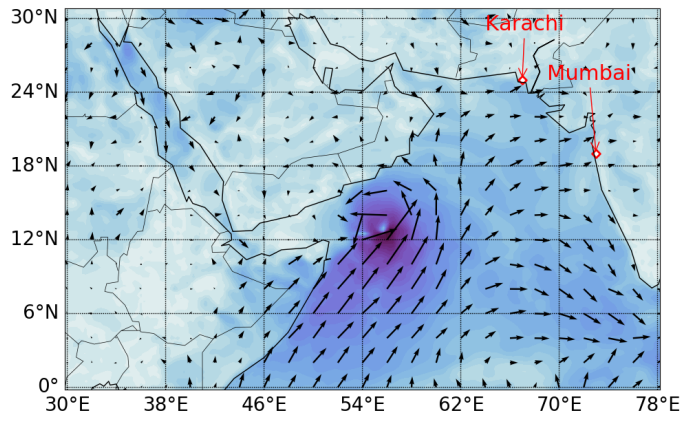

(b) UTC 0000, 05/26

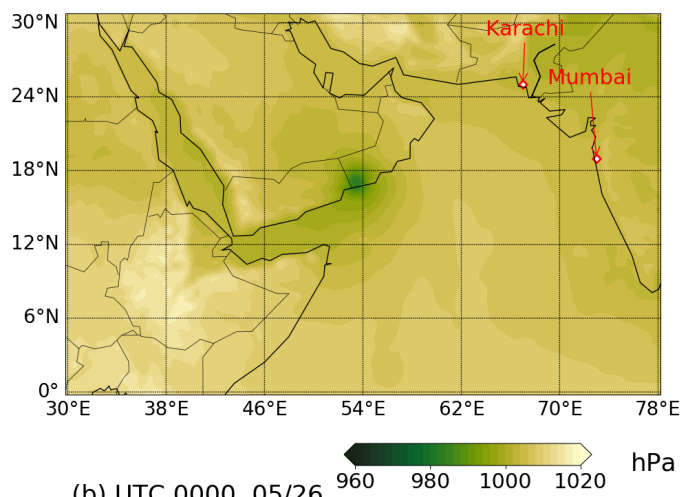

(b) UTC 0000,05/26 $960 \quad 980 \quad 1000 \quad 1020 \quad \mathrm{hPa}$

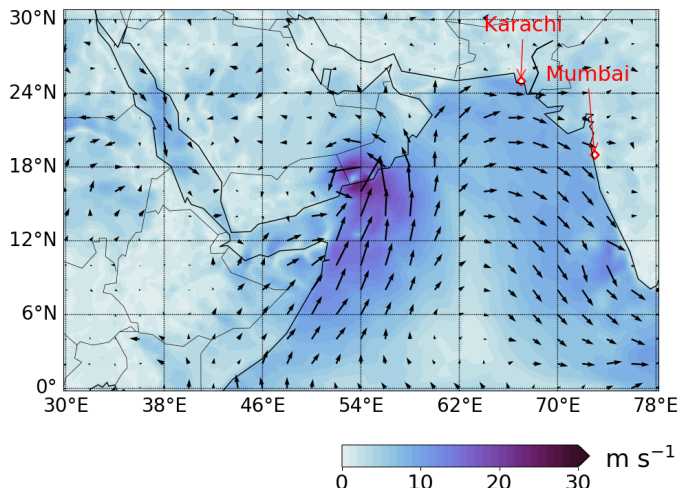

Figure 1. Snapshots of sea level pressure and wind speed during Cyclone Mekunu. Panels (a-b) show the contours of sea level pressure from ERA5; Panels (c-d) show 10-m wind speed from ERA5. The arrows in Panels $(\mathrm{c}-\mathrm{d})$ indicate the wind direction. 
$H_{s}$ in WAV.CUR run

(a) UTC $0000,05 / 24$

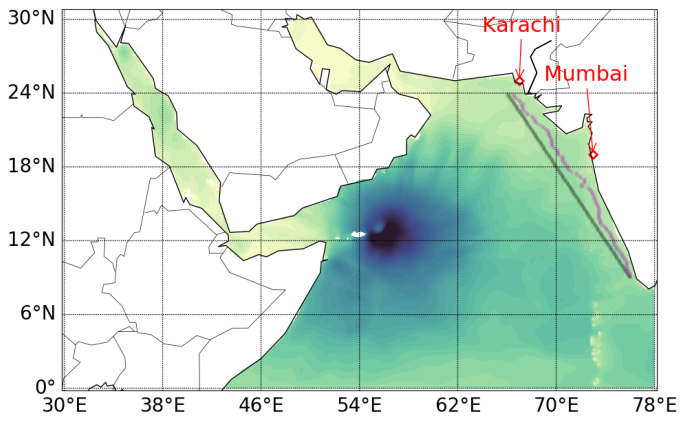

$H_{S}$ in WAV.WND run

(c) UTC 0000, 05/24

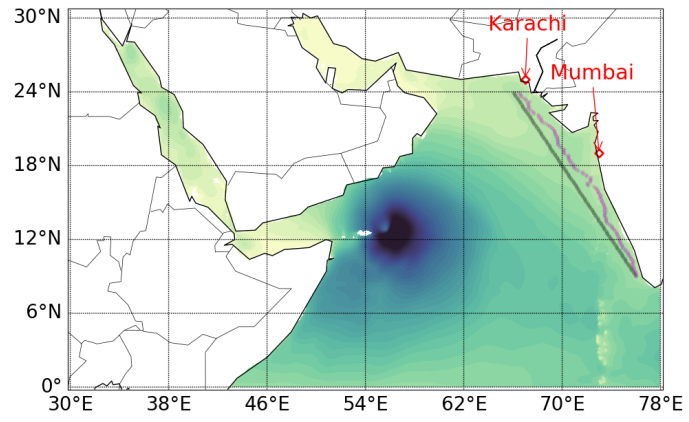

(b) UTC 0000, 05/26

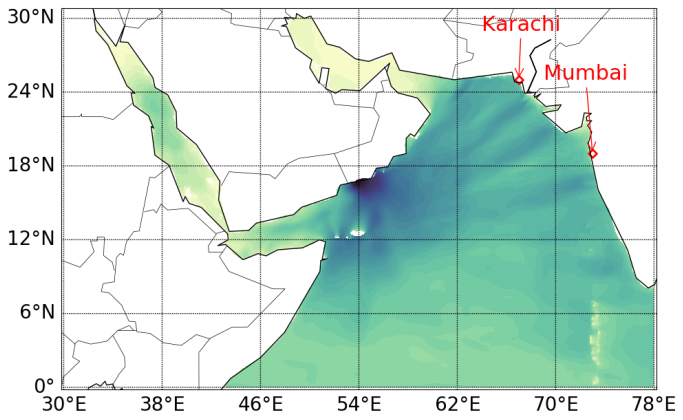

(d) UTC 0000, 05/26

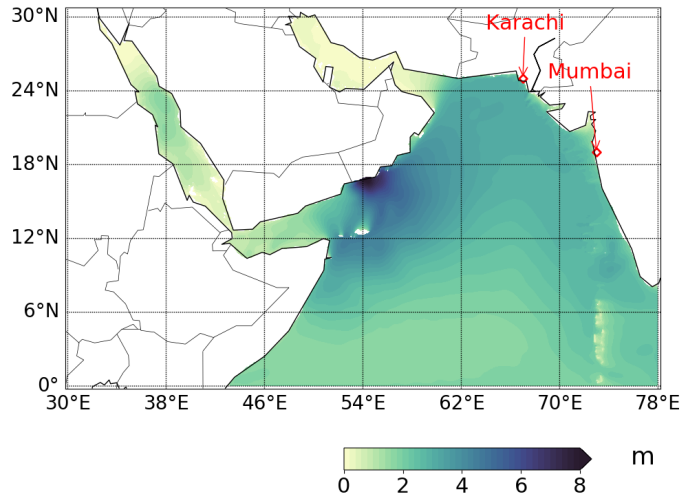

Figure 2. Snapshots of wave height $H_{s}$ obtained from the simulations. Panels $(\mathrm{a}-\mathrm{b})$ show $H_{s}$ from WAV.CUR run; Panels (c-d) show $H_{s}$ from WAV.WND run. In Panels (a) and (c), the black lines indicate the location where the wave heights were sampled in Fig. 6; the magenta lines indicate the $100 \mathrm{~m}$ isobath. 
$H_{s}$ WAV.CUR - WAV.WND

(a) UTC 0000, 05/24

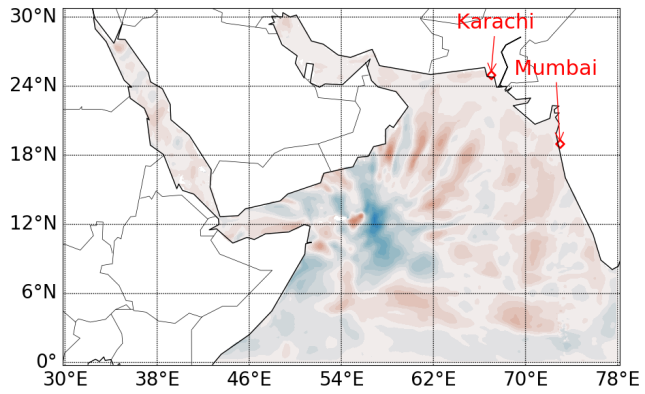

$H_{s}$ WAV.CUR_STA - WAV.WND

(c) UTC 0000, 05/24

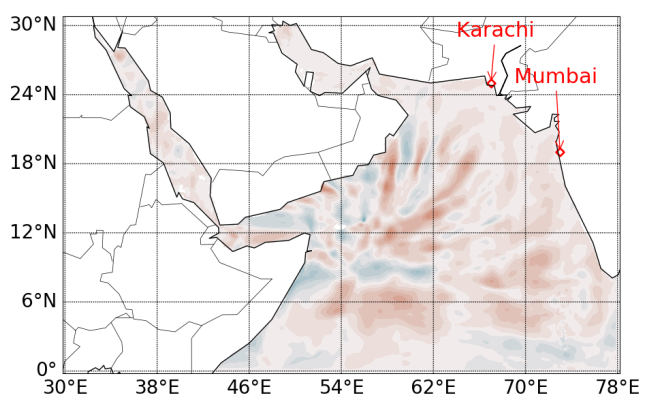

$H_{S}$ WAV.CUR_LOW - WAV.WND

(e) UTC 0000, 05/24

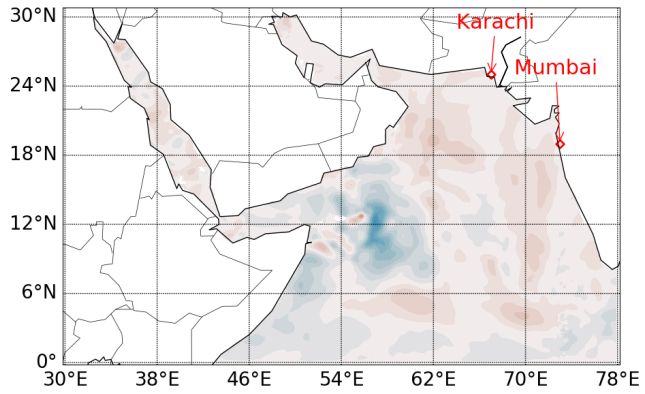

(b) UTC 0000, 05/26

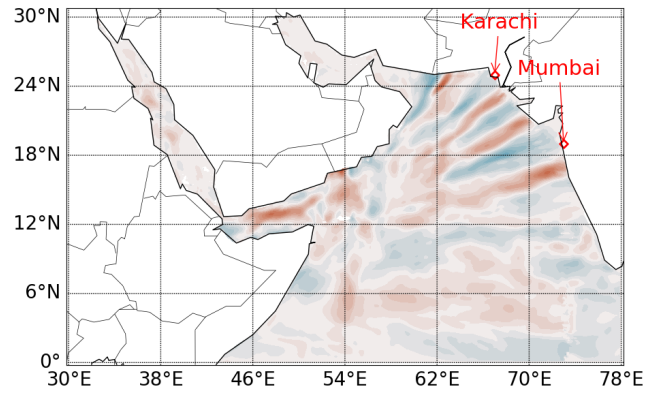

(d) UTC 0000, 05/26

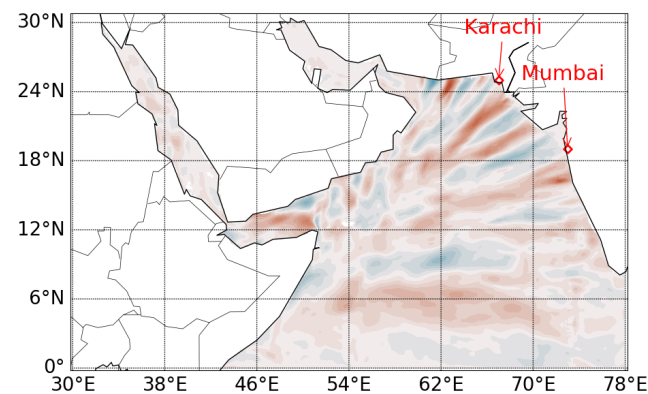

(f) UTC 0000, 05/26

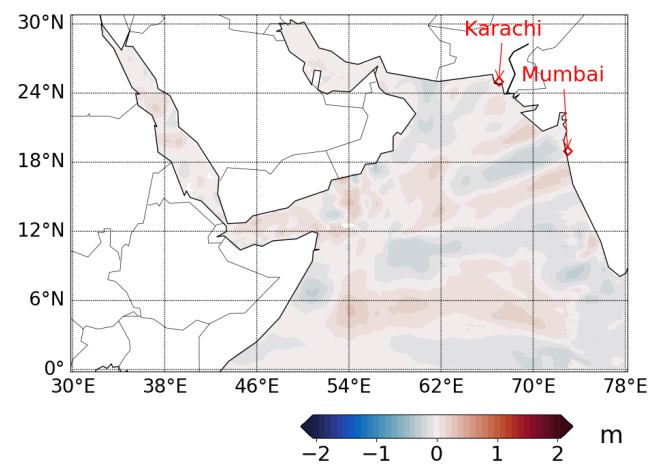

Figure 3. Difference of significant wave height $H_{s}$ between the simulations. Panels (a-b) show $H_{s}$ differences between WAV.CUR and WAV.WND; Panels (c-d) show $H_{s}$ differences between WAV.CUR_STA and WAV.WND; Panels (e-f) show $H_{s}$ differences between WAV.CUR_LOW and WAV.WND. 
in comparison with Jason-3

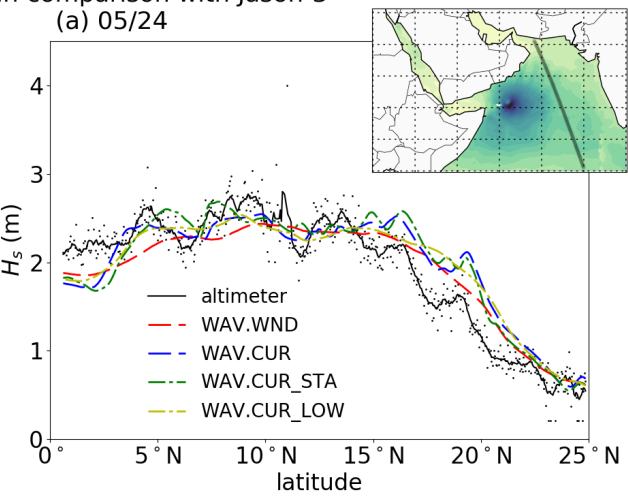

in comparison with SARAL/AItiKa

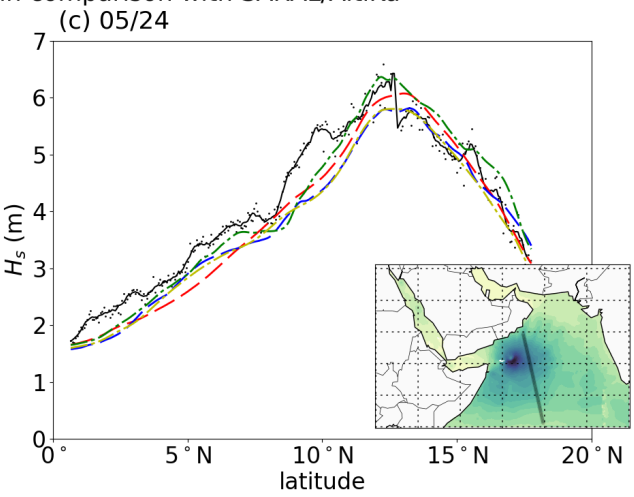

(b) $05 / 26$

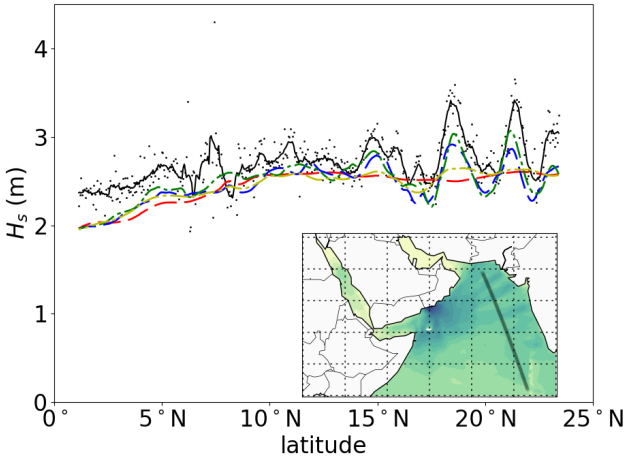

(d) $05 / 25$

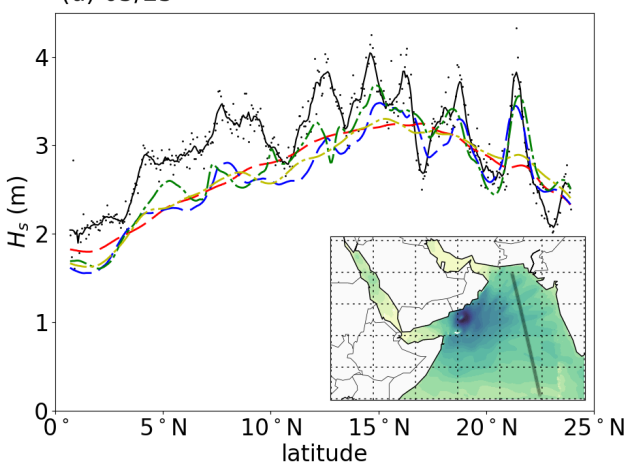

Figure 4. Comparison of significant wave height $H_{s}$ between the simulations and altimeter data. Panels (a-b) show the comparison with JASON-3 for May 24 and 26; Panels (c-d) show the comparison with SARAL for May 24 and 25. Black dots correspond to the altimetry data, while in the solid black line the data are smoothed with a moving average of $0.5^{\circ}$. The altimeter tracks are highlighted in the inset figures. The scale of the filled contours in the insets is consistent with that in Fig. 2.

To quantify the differences between each model run, we compute the correlation coefficient between model and observation along each satellite track. Since this paper focuses on the effects of currents on waves, which are more pronounced at shorter spatial scales, the correlation coefficient was computed after removing the $600 \mathrm{~km}$ low-pass signal from each track, shown in Fig. 5. We used the $600 \mathrm{~km}$ "box-car" low-pass filter because this distance is slightly larger than the distance between two consecutive beams in Fig. 2. Using the high-pass filtered $H_{s}$ highlights the correlation of $H_{s}$ on scales shorter than $600 \mathrm{~km}$, with correlation coefficients given in Table 1. The correlation coefficient values are dependent on the bandwidth of the filter. However, as long as the size of the filter is larger than the distance between high and low beams, the correlation coefficients 
of WAV.CUR and WAV.CUR_STA at three representative snapshots (Jason-3 05/24, 05/26, and AltiKa 05/25) are higher. This is because WAV.CUR and WAV.CUR_STA better capture the alternating patterns of $H_{s}$, shown in Fig. 4 . It is noted that if we select a larger window length (e.g., 700 or $800 \mathrm{~km}$ ), the correlation coefficients are not significantly different.

\begin{tabular}{lcccc}
\hline Experiment & \multicolumn{2}{c}{ Jason-3 } & \multicolumn{2}{c}{ SARAL/AltiKa } \\
& $05 / 24$ & $05 / 26$ & $05 / 24$ & $05 / 25$ \\
& Fig. 2a & Fig. 2b & Fig. 2c & Fig. 2d \\
\hline WAV.WND & 0.08 & 0.02 & 0.40 & 0.26 \\
WAV.CUR & 0.41 & 0.62 & 0.46 & 0.70 \\
WAV.CUR_STA & 0.28 & 0.63 & 0.52 & 0.56 \\
WAV.CUR_LOW & 0.27 & 0.51 & 0.40 & 0.51 \\
\hline
\end{tabular}

Table 1. Comparison of the correlation coefficients between modeled and observed significant wave height $H_{s}$ along each satellite track after removing the $600 \mathrm{~km}$ low-pass signal.

\subsection{Temporal Evolution of Significant Wave Height Along the Coast}

The effects of currents in producing along-coast gradients in the wave field are emphasized by analyzing the temporal evolution of $H_{s}$ from the four model runs in a quasialongshore section that closely follows the $100 \mathrm{~m}$ isobath between $9^{\circ} \mathrm{N}, 76^{\circ} \mathrm{E}$ and $24^{\circ} \mathrm{N}$, $66^{\circ} \mathrm{E}$ (black line in Fig. 2). The discrete high and low beams of $H_{s}$ near the $100 \mathrm{~m}$ isobath of the east coast of the Arabian Sea that were observed in Fig. 2 are shown in greater detail in Hovmöller diagrams (Fig. 6). The significant wave heights in all simulations peak around May 26; however, the spatial variability of $H_{s}$ is notably different among the four panels. A remarkable feature revealed by Fig. 6 is that when the effects of full resolution currents are taken into account (WAV.CUR and WAV.CUR_STA), the maximum wave heights near $17^{\circ} \mathrm{N}, 21^{\circ} \mathrm{N}$, and $23^{\circ} \mathrm{N}$ are higher than those in WAV.WND by over $30 \%$. Also, the time period with high wave heights (e.g., $H_{s}>3 \mathrm{~m}$ ) lasts longer in WAV.CUR and WAV.CUR_STA than WAV.WND. In agreement with what was shown in the altimetry comparison in Fig. 4, spatial gradients of $H_{s}$ are much weaker in WAV.CUR_LOW than in the case of WAV.CUR and WAV.CUR_STA.

\subsection{Ray-Tracing Analysis}

Surface currents can modify the amplitude, direction, and wavenumber of surface waves. In particular, current vorticity $\zeta=\partial v / \partial x-\partial u / \partial y$ causes wave rays to bend (i.e. refract) such that the wave propagation deviates from a straight line and, as a result, focusing and defocusing of wave energy occurs. Further validation of this mechanism was achieved by turning off the refraction term in WW3 (see Supplementary Information), which resulted in smooth $H_{s}$ fields that were nearly indistinguishable from the run without current forcing (on May 26, the RMS difference is $0.10 \mathrm{~m}$ ). However, for better visualization of the processes leading to the alternating high and low beams of significant wave height observed during Tropical Cyclone Mekunu we performed a raytracing analysis (Phillips, 1966; Dysthe, 2001) (see Supplementary Information for details) using a surface current snapshot from May 24 and a wave period of $10.2 \mathrm{~s}$, which is the peak period near the eyewall of the tropical cyclone (Fig. 7b). We propagated 61 equally-spaced rays starting from the eyewall with initial directions ranging from $195^{\circ}$ to $255^{\circ}$ (propagating to the northeast), which roughly encompasses the range of peak directions observed in the model output (Fig. 7a, red box). 

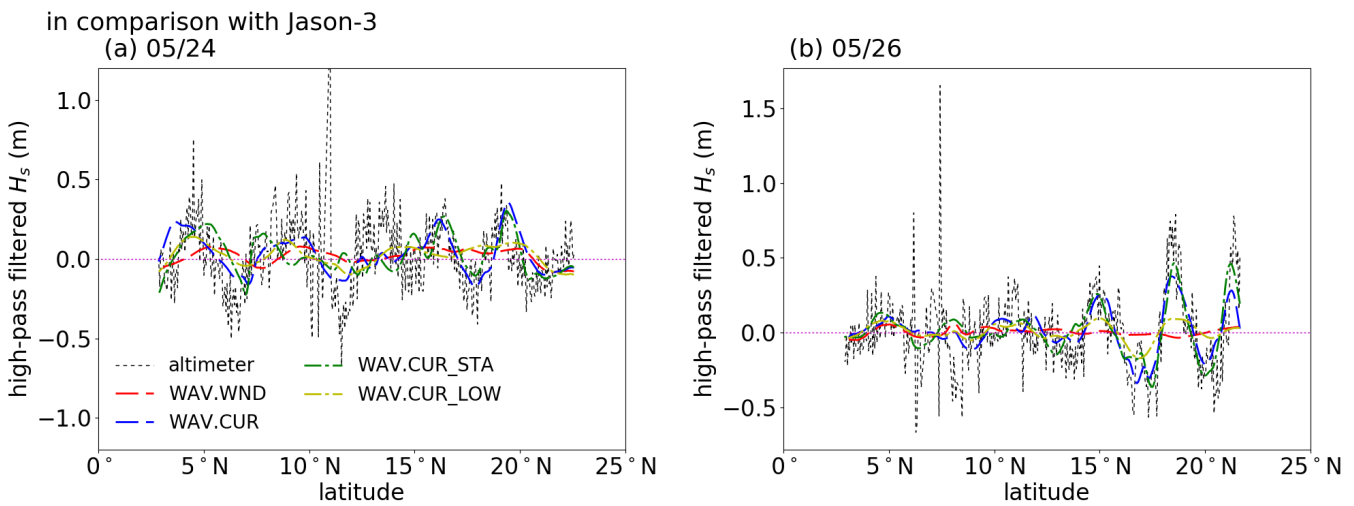

in comparison with SARAL/AltiKa
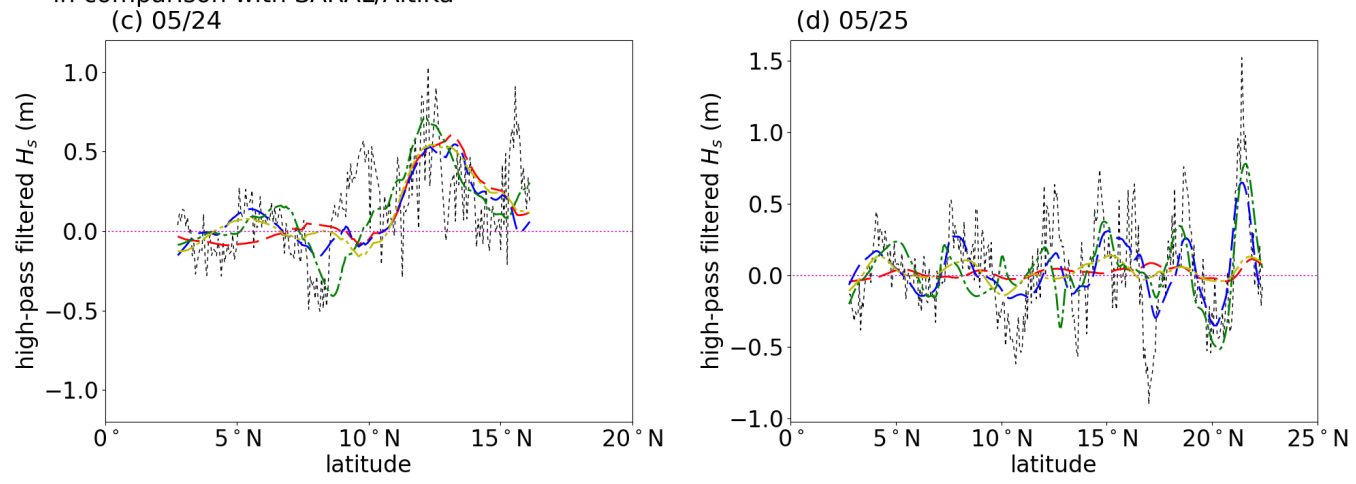

Figure 5. The wave height along the altimeter tracks after high-pass filtering scales longer than approximately $600 \mathrm{~km}$. Panels (a-b) show the filtered data of JASON-3 for May 24 and 26; Panels (c-d) show the filtered data of SARAL for May 24 and 25. 

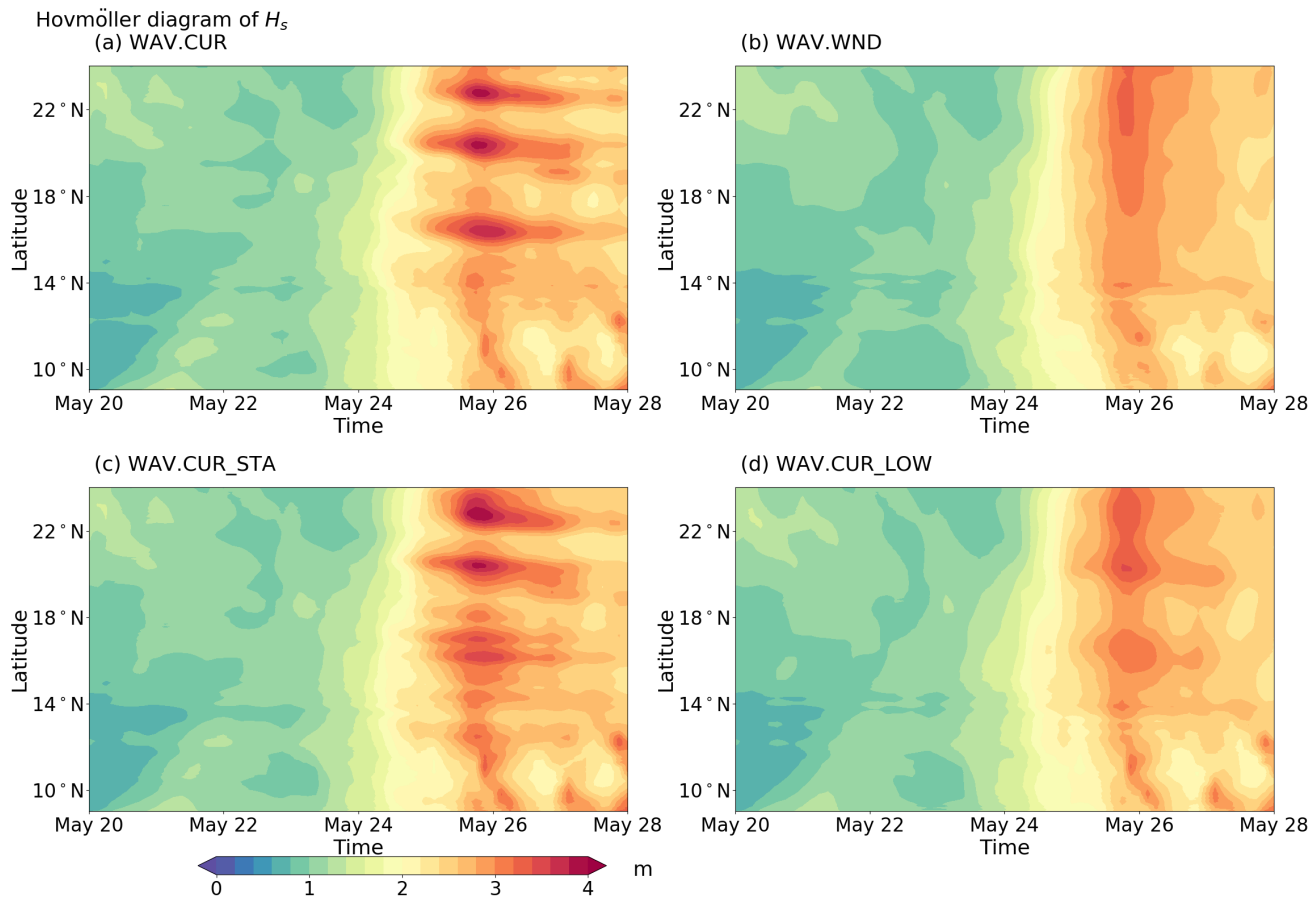

Figure 6. Spatial-temporal evolution of significant wave height $H_{s}$ near the $100 \mathrm{~m}$ isobath of the east coast of the Arabian Sea. Panels (a-d) show the Hovmöller diagrams of WAV.CUR, WAV.WND, WAV.CUR_STA, and WAV.CUR_LOW, respectively.

Figure 8a shows that locations with high and low concentration of rays (black lines) are generally consistent with the alternating high (red) and low (blue) beams of significant wave height shown in the background as a colormap. The discrepancy between the theoretical ray-tracing analysis and WW3 model can be attributed to a number of reasons. First, the ray-tracing performed here only considers monochromatic waves radiating from the eyewall of the tropical cyclone. Here, we also only show the ray-tracing results for waves initially at the peak frequency in our WW3 simulations. Additionally, the ray-tracing analysis assumes that the background currents are stationary during the propagation of the waves. In comparion with WAV.CUR, ray-tracing performed using currents from May 20 (WAV.CUR_STA, Fig. 8b) results in similar patterns of focusing and defocusing of rays despite some notable differences. When the currents are smoothed (WAV.CUR_LOW, Fig. 8c), wave rays propagate in nearly straight lines and remain uniformly spaced.

Further interpretation of the ray paths is performed by considering the current vorticity field (Fig. 9). Assuming the group speed of the waves, $c_{g}$, is much larger than the current speed implies the ray curvature, $\chi$, is approximated by (Kenyon, 1971; Dysthe, 2001)

$$
\chi=\zeta / c_{g} .
$$

Thus $10 \mathrm{~s}$ period waves propagating with a group speed of $8 \mathrm{~m} \mathrm{~s}^{-1}$ over a distance of $200 \mathrm{~km}$ in a current field with a mean vorticity of $2 \times 10^{-5} \mathrm{~s}^{-1}$ would be deflected by approximately $29^{\circ}$. Equation (7) shows that positive (cyclonic) vorticity causes rays to bend to the left, while negative (anti-cyclonic) vorticity causes rays to bend to the right. In Fig. 9b we see a patch of positive vorticity (green) near $16^{\circ} \mathrm{N}, 62^{\circ} \mathrm{E}$ followed by a patch of negative vorticity (brown) just south of it. These regions of opposing vorticity cause the rays to diverge, resulting in an overall low concentration of rays to the northeast of 
(a) peak direction, UTC 0000, 05/24

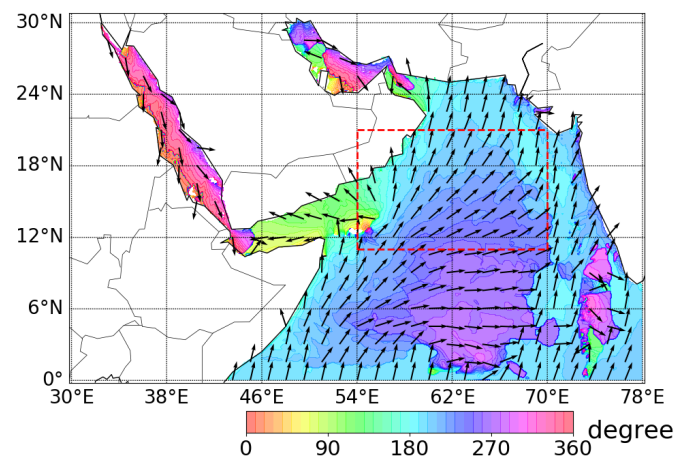

(b) wave period, UTC 0000, 05/24

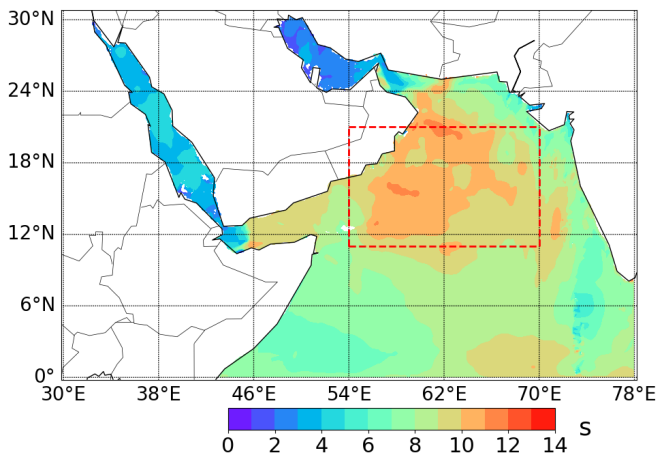

Figure 7. Peak direction and mean wave period obtained from WAV.CUR. Panel (a) shows the peak direction of the waves; Panel (b) shows the mean wave period in WAV.CUR. The arrows in Panel (a) denote the direction of the waves.
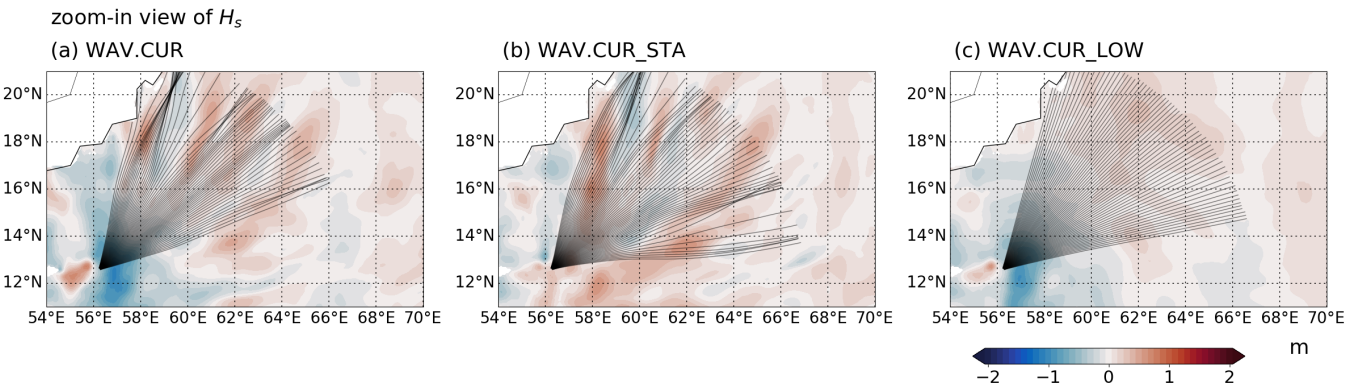

Figure 8. Ray-tracing analysis of the waves generated from the eyewall of the tropical cyclone on May 24. Panels $(\mathrm{a}-\mathrm{c})$ show ray-tracing analysis results superimposed for WAV.CUR, WAV.CUR_STA, and WAV.CUR_LOW, respectively. The background contours indicate $H_{s}$ obtained from WAV.CUR, WAV.CUR_STA, and WAV.CUR_LOW in comparison with WAV.WND. 
$16^{\circ} \mathrm{N}, 62^{\circ} \mathrm{E}$. This deflection of rays in opposite directions is even more explicit in WAV.CUR_STA (Fig. 9c), where the vorticity to the northeast of the cyclone is stronger in comparison to WAV.CUR. When the surface currents are smoothed in WAV.CUR_LOW, most of the mesoscale energy is suppressed and the resulting vorticity is much weaker in comparison with WAV.CUR and WAV.CUR_STA. As a consequence, there is no significant refraction, and the significant wave height is nearly uniform in the azimuthal direction.

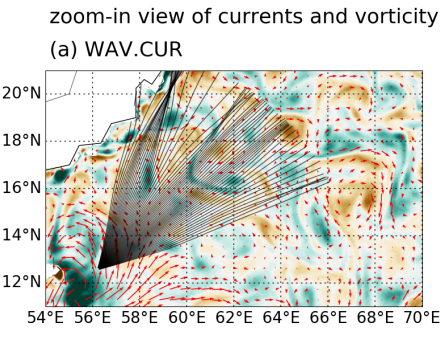

\section{(b) WAV.CUR_STA}

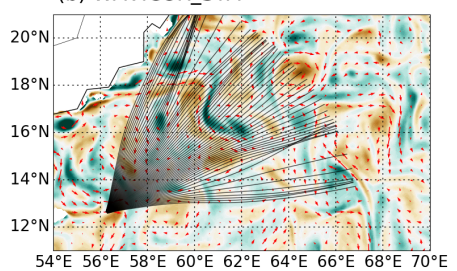

(c) WAV.CUR_LOW

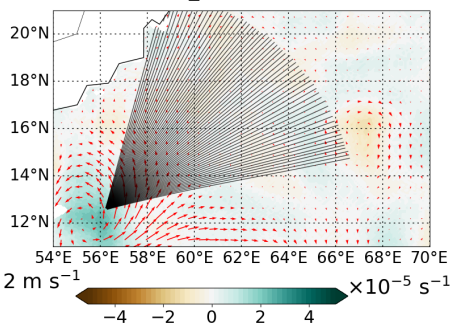

Figure 9. Ray-tracing analysis plotted on top of the vorticity and currents. Panels $(\mathrm{a}-\mathrm{c})$ show ray-tracing analysis results for WAV.CUR, WAV.CUR_STA, and WAV.CUR_LOW, respectively.

\section{Discussion}

Recent observational and modeling studies have highlighted the importance of wavecurrent interactions in determining the sea state. In particular, these studies suggest that at oceanic meso- and submesoscales the spatial gradients in the significant wave height field arise from focusing and defocusing of wave action due to refraction by ocean currents(Ardhuin et al., 2017; Villas Bôas et al., 2020; Marechal \& Ardhuin, 2021). To better understand the impact of currents on tropical-cyclone generated waves, here we used a regional wave model to show that including mesoscale currents in a tropical cyclone simulation leads to alternating regions of high and low $H_{s}$ starting near the eyewall and extending to the northeast all the way to $100 \mathrm{~m}$ isobath. The spatial variability in $H_{s}$ observed in the model simulations is consistent with the available altimeter data (the RMS difference between WAV.CUR and altimeter data is $0.37 \mathrm{~m}$ ), and reveals ocean current-driven variations in $H_{s}$ up to approximately $2 \mathrm{~m}$ (e.g., on May $25 \mathrm{th}, H_{s}$ varies from $1.9 \mathrm{~m}$ to $3.9 \mathrm{~m}$ between $20^{\circ} \mathrm{N}$ and $25^{\circ} \mathrm{N}$ from SARAL/Altika data).

Wave ray-tracing through the ocean currents gives understanding of the observed patterns of focusing and defocusing of wave energy and the resulting $H_{s}$ structure. Although one previous study focused on the effects of cyclone-induced surface currents on the sea state(Fan, Ginis, \& Hara, 2009), both our WW3 simulations and ray-tracing analysis suggest that the spatial gradients in $H_{s}$ are dominated by the background currents and are not significantly influenced by the tropical cyclone induced currents. Importantly, this simplifies the problem of predicting these wave state gradients. The existing background cyclonic and anti-cyclonic eddies cause the cyclone induced rays to bend in opposite directions, creating regions of high and low ray concentration. The strength of eddy vorticity leads to stronger refraction (higher ray curvature). This is demonstrated here by comparing ray trajectories using fully resolved currents (WAV.CUR) and smoothed currents (WAV.CUR_LOW); when the spatial variability of the currents is suppressed the eddies are not strong enough to cause significant deflections in the ray trajectories and regions of amplified $H_{s}$ are not simulated. Here we show that including ocean surface current forcing in the wave model leads to spatial gradients of $H_{s}$ that better correlate with altimetry observations. It is possible that small spatiotemporal-scale winds 
not resolved by ERA5 could also affect the observed structure in $H_{s}$. Future work should assess the relative impact of high-frequency, high-wavenumber wind variability and ocean currents on surface ocean wave variability.

Waves provide much of the energy driving coastal and beach erosion, flooding, and wave overtopping(Young et al., 2021), making accurate wave modeling of paramount importance for adaptation and mitigation efforts in response to extreme events. Although there has been significant improvement in weather and wave forecasting systems, most operational wave models exclude current forcing(Ardhuin et al., 2012). This paper demonstrates that background mesoscale currents affect cyclone-generated waves, leading to spatial gradients in the significant wave height. Importantly, for some regions the currents amplify the wave heights by $1 \mathrm{~m}$. Although we focused the discussion on Cyclone Mekunu, the same spatial pattern of amplified and diminished beams of $H_{s}$ was observed during other tropical cyclones (see Supplementary Information). This suggests the findings here are a general feature of tropical-cyclone-generated waves in the Arabian Sea due to interactions with background currents. Variations in the total water level represent a major hazard for densely populated coastal areas. The contribution of surface waves to the total water level can be generally parameterized as a function of the offshore significant wave height and period (Dodet et al., 2019). Here we have shown that when the effects of currents are not taken into account the modelled wave heights at some major cities on the Arabian Sea coast can be underestimated by up to $1 \mathrm{~m}$. This translates into a significant underestimation of the wave-driven contribution to the total water level and presents a clear risk to the coastal population.

\section{Acknowledgments}

We gratefully acknowledge the research funding (grant number: OSR-2-16-RPP-3268.02) from KAUST (King Abdullah University of Science and Technology). We also appreciate the computational resources related to the supercomputer Shaheen II and the assistance provided by KAUST Supercomputer Laboratory. A.B.V.B. was funded by the SWOT program with NASA grants NNX16AH67G and 80NSSC20K1136. We wish to thank Fabrice Ardhuin for discussing the simulation results and the setup of the numerical simulations.

\section{Data Availability Statement}

The simulation results are available at: https://doi.org/10.5281/zenodo.4660321.

\section{Code Availability}

We used WAVEWATCH III version 5.16 compiled with the following switches: F90 NOGRB NOPA LRB4 SCRIP SCRIPNC NC4 TRKNC DIST MPI PR3 UQ FLX0 LN1 ST4 STAB0 NL1 BT4 DB1 MLIM TR0 BS0 IC2 IS2 REF1 IG0 XX0 WNT2 WNX1 RWND CRT1 CRX1 TIDE O0 O1 O2 O2a O2b O2c O3 O4 O5 O6 O7.

\section{Author contributions statement}

All authors conceived the experiments; R.S. set up the WAVEWATCH III model and conducted the numerical simulations; R.S. and A.B.V.B. conducted the ray-tracing analysis; R.S. plotted the figures; R.S., A.B.V.B., and A.S. drafted the initial manuscript; all authors discussed the results and revised the manuscript.

\section{Competing Interests}

The authors declare no competing interests. 


\section{References}

Abolfazli, E., Liang, J.-H., Fan, Y., Chen, Q. J., Walker, N. D., \& Liu, J. (2020). Surface gravity waves and their role in ocean-atmosphere coupling in the Gulf of Mexico. Journal of Geophysical Research: Oceans, 125(7), e2018JC014820.

Alday, M., Accensi, M., Ardhuin, F., \& Dodet, G. (2021). A global wave parameter database for geophysical applications. part 3: Improved forcing and spectral resolution. Ocean Modelling, 166, 101848.

Ardhuin, F., Gille, S. T., Menemenlis, D., Rocha, C. B., Rascle, N., Chapron, B., ... Molemaker, J. (2017). Small-scale open ocean currents have large effects on wind wave heights. Journal of Geophysical Research: Oceans, 122(6), 4500-4517.

Ardhuin, F., Roland, A., Dumas, F., Bennis, A.-C., Sentchev, A., Forget, P., ... Benoit, M. (2012). Numerical wave modeling in conditions with strong currents: Dissipation, refraction, and relative wind. Journal of Physical Oceanography, 42(12), 2101-2120.

Booij, N., \& Holthuijsen, L. H. (1987). Propagation of ocean waves in discrete spectral wave models. Journal of Computational Physics, 68(2), 307-326.

Cavaleri, L., Fox-Kemper, B., \& Hemer, M. (2012). Wind waves in the coupled climate system. Bulletin of the American Meteorological Society, 93(11), 16511661.

Chassignet, E. P., Hurlburt, H. E., Smedstad, O. M., Halliwell, G. R., Hogan, P. J., Wallcraft, A. J., .. Bleck, R. (2007). The HYCOM (hybrid coordinate ocean model) data assimilative system. Journal of Marine Systems, 65(1), 60-83.

Chen, S. S., Zhao, W., Donelan, M. A., \& Tolman, H. L. (2013). Directional windwave coupling in fully coupled atmosphere-wave-ocean models: Results from CBLAST-Hurricane. Journal of the Atmospheric Sciences, 70(10), 3198-3215.

Dodet, G., Melet, A., Ardhuin, F., Bertin, X., Idier, D., \& Almar, R. (2019). The contribution of wind-generated waves to coastal sea-level changes. Surveys in Geophysics, 40(6), 1563-1601.

Drost, E. J. F., Lowe, R. J., Ivey, G. N., Jones, N. L., \& Péquignet, C. A. $\quad$ (2017). The effects of tropical cyclone characteristics on the surface wave fields in Australia's North West region. Continental Shelf Research, 139, 35-53.

Dube, S. K., Rao, A. D., Sinha, P. C., Murty, T. S., \& Bahulayan, N. (1997). Storm surge in the Bay of Bengal and Arabian Sea the problem and its prediction. Mausam, 48(2), 283-304.

Dysthe, K. B. (2001). Refraction of gravity waves by weak current gradients. Journal of Fluid Mechanics, 442, 157.

ECMWF. (2017). Era5 data documentation (Tech. Rep.). European Center for Medium-Range Weather Forecasts.

Evan, A. T., \& Camargo, S. J. (2011). A climatology of Arabian Sea cyclonic storms. Journal of Climate, 24(1), 140-158.

Evan, A. T., Kossin, J. P., \& Ramanathan, V. (2011). Arabian Sea tropical cyclones intensified by emissions of black carbon and other aerosols. Nature, 479(7371), 94-97.

Fan, Y., Ginis, I., \& Hara, T. (2009). The effect of wind-wave-current interaction on air-sea momentum fluxes and ocean response in tropical cyclones. Journal of Physical Oceanography, 39(4), 1019-1034.

Fan, Y., Ginis, I., Hara, T., Wright, C. W., \& Walsh, E. J. (2009). Numerical simulations and observations of surface wave fields under an extreme tropical cyclone. Journal of Physical Oceanography, 39(9), 2097-2116.

Government of India, I. M. D., Ministry of Earth Sciences. (2018). Extremely severe cyclonic storm, "mekunu" over the arabian sea (21-27 may 2018): A report. (Tech. Rep.). New Delhi: India Meteorological Department. Retrieved from http://www.rsmcnewdelhi.imd.gov .in/index . php?option= 
com_content\&view=article\&id=198: preliminary-report-2018\&catid=12: publications\&Itemid $=540 \& l$ ang $=e n$.

Hegermiller, C. A., Warner, J. C., Olabarrieta, M., \& Sherwood, C. R.

Wave-current interaction between Hurricane Matthew wave fields and the Gulf Stream. Journal of Physical Oceanography, 49(11), 2883-2900.

Holthuijsen, L. H., \& Tolman, H. L. (1991). Effects of the Gulf Stream on ocean waves. Journal of Geophysical Research: Oceans, 96(C7), 12755-12771.

Kenyon, K. E. (1971). Wave refraction in ocean currents. Deep Sea Research and Oceanographic Abstracts, 18(10), 1023 - 1034. Retrieved from http://www.sciencedirect.com/science/article/pii/0011747171900064 doi: https://doi.org/10.1016/0011-7471(71)90006-4

Liu, Q., Babanin, A., Fan, Y., Zieger, S., Guan, C., \& Moon, I.-J. (2017). Numerical simulations of ocean surface waves under hurricane conditions: Assessment of existing model performance. Ocean Modelling, 118, 73-93.

Marechal, G., \& Ardhuin, F. (2021). Surface currents and significant wave height gradients: Matching numerical models and high-resolution altimeter wave heights in the agulhas current region. Journal of Geophysical Research: Oceans, 126(2), e2020JC016564.

Mogensen, K. S., Magnusson, L., \& Bidlot, J.-R. (2017). Tropical cyclone sensitivity to ocean coupling in the ECMWF coupled model. Journal of Geophysical Research: Oceans, 122(5), 4392-4412.

Munk, W. H., \& Traylor, M. A. (1947). Refraction of ocean waves: a process linking underwater topography to beach erosion. The Journal of Geology, 55(1), $1-26$.

Murakami, H., Vecchi, G. A., \& Underwood, S. (2017). Increasing frequency of extremely severe cyclonic storms over the Arabian Sea. Nature Climate Change, $7(12), 885-889$.

Olabarrieta, M., Warner, J. C., Armstrong, B., Zambon, J. B., \& He, R. Ocean-atmosphere dynamics during Hurricane Ida and Nor'Ida: an application of the coupled ocean-atmosphere-wave-sediment transport (COAWST) modeling system. Ocean Modelling, 43, 112-137.

Phillips, O. (1966). The Dynamics of the Upper Ocean. Cambridge University Press.

Prakash, K. R., \& Pant, V. (2020). On the wave-current interaction during the passage of a tropical cyclone in the Bay of Bengal. Deep Sea Research Part II: Topical Studies in Oceanography, 172, 104658.

Queffeulou, P., \& Croizé-Fillon, D. (2013). Global altimeter SWH data set, version 10. (Tech. Rep.). Laboratoire d'Océanographie Spatiale, IFREMER, Plouzané, France. Available at ftp://ftp.ifremer.fr/ifremer/cersat/products/ swath/altimeters/waves/.

Quilfen, Y., \& Chapron, B. (2019). Ocean surface wave-current signatures from satellite altimeter measurements. Geophysical Research Letters, 46(1), 253261.

Quilfen, Y., Yurovskaya, M., Chapron, B., \& Ardhuin, F. (2018). Storm waves focusing and steepening in the Agulhas current: Satellite observations and modeling. Remote sensing of Environment, 216, 561-571.

Rascle, N., \& Ardhuin, F. (2013). A global wave parameter database for geophysical applications. Part 2: Model validation with improved source term parameterization. Ocean Modelling, 70, 174-188.

Romero, L., Hypolite, D., \& McWilliams, J. C. (2020). Submesoscale current effects on surface waves. Ocean Modelling, 153, 101662.

Tolman, H. L. (2002). Alleviating the garden sprinkler effect in wind wave models. Ocean Modelling, 4(3-4), 269-289.

Villas Bôas, A. B., Ardhuin, F., Ayet, A., Bourassa, M. A., Brandt, P., Chapron, B., ... others (2019). Integrated observations of global surface winds, cur- 
rents, and waves: requirements and challenges for the next decade. Frontiers in Marine Science, 6, 425 .

Villas Bôas, A. B., Cornuelle, B., Mazloff, M., Gille, S., \& Ardhuin, F.

Wave-current interactions at meso-and submesoscales: Insights from idealized numerical simulations. Journal of Physical Oceanography, 50(12), 3483-3500.

Warner, J. C., Armstrong, B., He, R., \& Zambon, J. B. (2010). Development of a coupled ocean-atmosphere-wave-sediment transport (COAWST) modeling system. Ocean Modelling, 35(3), 230-244.

WAVEWATCH III Development Group. (2016). User manual and system documentation of WAVEWATCH III version 5.16. NOAA/NWS/NCEP/MMAB Technical Note 329, 326.

Young, A. P., Guza, R. T., Matsumoto, H., Merrifield, M. A., O’Reilly, W. C., \& Swirad, Z. M. (2021). Three years of weekly observations of coastal cliff erosion by waves and rainfall. Geomorphology, 375, 107545. 